\title{
Assessment of a new technique of hemoconcentration and the necessities of blood derivates for transfusion in patients submitted to heart surgery using cardiopulmonay bypass
}

\author{
Avaliação de nova técnica de hemoconcentração e da necessidade de transfusão de hemoderivados em \\ pacientes submetidos à cirurgia cardíaca com circulação extracorpórea
}

\section{Abstract}

Objective: To assess a new technique of hemoconcentration and the necessity of blood component transfusion.

Method: Eighty-six male (61.4\%) and 54 female (38.6\%) patients submitted to heart surgery under cardiopulmonary bypass were divided into two groups of 70 patients each according to conventional technique of blood preparation (Group $A$ ) and the use of the new technique of hemoconcentration (Group B).

Results: The hemoconcentration technique is feasible and did not alter the intra- and postoperative complications of the patients. The amount of blood and plasma used during and after cardiopulmonary bypass was less in Group B patients. Moreover, the fluid balance after cardiopulmonary bypass in this group was better when compared to the Group A patients.
Conclusions: The new technique of hemoconcentration was efficient regarding removal of fluids, allowed a better use of oxygenator residual contents and decreased the amount of blood components used during and after cardiopulmonary bypass.

Descriptors: Hemofiltration, methods. Cardiac Surgical procedures. Blood transfusion, autologous, method. Extracorporeal circulation, methods.

Resumo

Objetivo: Avaliar uma nova técnica de hemoconcentração e a necessidade de transfusão de hemoderivados.

Método: Foram estudados 140 indivíduos adultos submetidos à cirurgia cardíaca com circulação extracorpórea (CEC), sendo 86 (61,4\%) do sexo masculino e $54(38,6 \%)$ do

Work performed in the Hospital de Base, Medicine School, São José do Rio Preto, Brazil.

1 - Hospital de Base, Medicine School, São José do Rio Preto, Brazil.

Correspondence address: Prof. Dr. Dulcimar Donizete de Souza Faculdade de Medicina de São José do Rio Preto

Av. Brig. Faria Lima 5416

São José do Rio Preto - SP - Brazil

15090-000

Article received on November, 2003

E-mail: dulcimards@hotmail.com 
feminino, divididos em dois grupos de acordo com a utilização ou não de uma nova técnica com hemoconcentrador. $O$ grupo A (sem hemoconcentrador) incluiu 70 pacientes e o B (com hemoconcentrador) 70 indivíduos.

Resultados: Esta técnica de hemoconcentração mostrouse factível, não acrescentando complicações intra e pósoperatórias para o paciente. Utilizou-se menor quantidade de sangue e de plasma durante e após CEC, nos indivíduos do grupo B. Também o balanço de líquidos, após CEC, neste

\section{INTRODUCTION}

Since the first on-pump surgery performed by GIBBON in 1953 [1], the development of cardiopulmonary bypasses (CPB) was very fast. Currently, $\mathrm{CPB}$ does not only substitute the cardiopulmonary functions but helps to maintain the cellular integrity, structure and function and the metabolism of the organs and individual systems, enabling more complex and longer operations [2].

The first attempts to use CPB in practice suggested that the most physiological conduct would be to fill the apparatus with fresh blood [1]. The demand for the use of blood caused an overload in blood banks and naturally limited the number of procedures [2]. An alternative was to use of blood preserved in a citrate solution, without the disadvantages of fresh heparinized blood [3]. However, patients the use of fresh or citrated homologous blood, presented a complex condition at the start of the perfusion characterized by arterial hypertension and a drop in the venous return. Other complications related to the use of homologous blood include hemolysis, denaturation of proteins and hepatitis, frequently with serious sequels [2].

With the aim of reducing the necessity of blood, PANICO \& NEPTUNE [4] in 1959 developed an oxygenator in which one part of the perfusate was saline solution. This system enabled many experimental and clinical studies to be made resulting in the concept of hemodilution. MORAIS et al. [5] were pioneers when in 1960 they introduced hemodilution using plasma in the oxygenator to replace the blood with an improvement of the oxygenation during perfusion.

On the other hand, an excessive hydric increase can result in complications and lead to the necessity of hemofiltration techniques. If the hemodilution is not carefully performed, hemoglobin levels may be reduced, diminishing the transportation and availability of oxygen to the tissues and hypoxia may occur despite of high $\mathrm{pO}_{2}$ levels in the arterial blood.

WALPOTH et al. [7] evaluated the quality of hemoconcentrated blood of 11 patients submitted to CPB with hemofiltration and compared these with 11 patients (control group) submitted to heart surgery using CPB but without hemofiltration. They confirmed that hemofiltration during CPB is a safe and efficacious method of removing grupo, foi menor quando comparado ao grupo $\mathrm{A}$.

Conclusões: Concluiu-se que a nova técnica de hemoconcentração foi eficaz na remoção de líquidos, permitiu maior aproveitamento do sangue remanescente no oxigenador e reduziu o uso de hemoderivados durante e pós-CEC.

Descritores: Hemofiltração, métodos. Procedimentos cirúrgicos cardíacos. Circulação extracorpórea, métodos. Transfusão de sangue autóloga, métodos.

water and to concentrate the red blood cells and proteins without adverse effects on the hemodynamics, quality of blood and volume requirements.

In the last decade, hemoconcentration in heart surgery using CPB has been greatly studied. The main advantages include filtration of the mediators of general inflammatory reactions [8], reduction in the quantity of circulating endotoxins [9], removal of excessive body water and reduction of pulmonary hypertension [10].

In Brazil the first works about hemofiltration during CPB were experimental [11], with later clinical application [12]. The hemofiltration technique was perfected and later modified by the team of Dr. Elliot, who moved the position of the hemofilter in the CPB circuit and thus the moment of its use [13].

Currently there are two methods of hemoconcentration: conventional and modified. In the conventional method, the hemoconcentrator is installed in the CPB circuit usually on the recirculation line of the oxygenator or by means of another pump to hemoconcentrate during CPB [12]. In the modified method, hemoconcentration is achieved by means of a pump, suctioning the blood from the aorta, flowing through the hemoconcentrator and re-entering the right atrium after $\mathrm{CPB}$ [13]

Owing to the scarcity of published national studies, there is a justification in evaluating the new method of hemoconcentration in patients submitted to heart surgery using CPB, which include hemoconcentration achieved at two stages during the CPB with a velocity of filtration dependent on the hematocrit levels and on the volume of blood in the venous reservoir and before infusion of the residual volume (arterial and venous blood) of the oxygenator of the patient, with the aim of reducing the necessity of blood and blood component transfusions in the postoperative period.

The objectives of this study were to evaluate a new technique of hemoconcentration during heart surgery with $\mathrm{CPB}$ with and without a hemoconcentrator and the necessity of blood component transfusion in patients.

\section{METHOD}

Eighty-six male (61.4\%) and 54 female (38.6\%) adult 
patients who were submitted to heart surgery using $\mathrm{CPB}$ were studied. The patients were allocated to two groups, Group A (without hemoconcentrator) comprised of 70 patients with ages ranging from 21 to 28 years $(55.1 \pm 14.3$ years) and Group B (with hemoconcentrator) comprised of 70 patients with ages ranging from 16 to 74 years $(54.8 \pm 13.6$ years). The body surface area was between 1.38 and $2.25 \mathrm{~m}^{2}$ $\left(1.74 \pm 0.16 \mathrm{~m}^{2}\right)$ for Group A and between 1.36 and $2.00 \mathrm{~m}^{2}$ $\left(1.71 \pm 0.17 \mathrm{~m}^{2}\right)$ for the patients in Group B. This study was approved by the Research Ethics Committee of the Medicine School, São José do Rio Preto, Brazil (Famerp).

All the patients were consulted in the Heart Surgery Department of Hospital de Base, São José do Rio Preto, São Paulo, in the period from 1999 to 2001.

During the surgery, to substitute the cardiopulmonary functions, a CPB BEC 2000 model pump composing of four modules (arterial, cardioplegia and two aspirators) and adult or pediatric membrane oxygenators (Braile Biomedica, São José do Rio Preto, Brazil) were utilized depending on the size of the patient.

To use the new technique, the hemoconcentrator was installed in the recirculation line using a Y-shaped connection to the cardioplegia system, with a $1 / 8$ " connection (from the venous reservoir outlet to before the rollers of the cardioplegia) and a $1 / 4$ " tube (from the cardioplegia outlet to the inlet of the hemoconcentrator using a Y-shaped connector $1 / 4 " \times 1 / 4 " x 1 / 4 ")($ Figure 1).

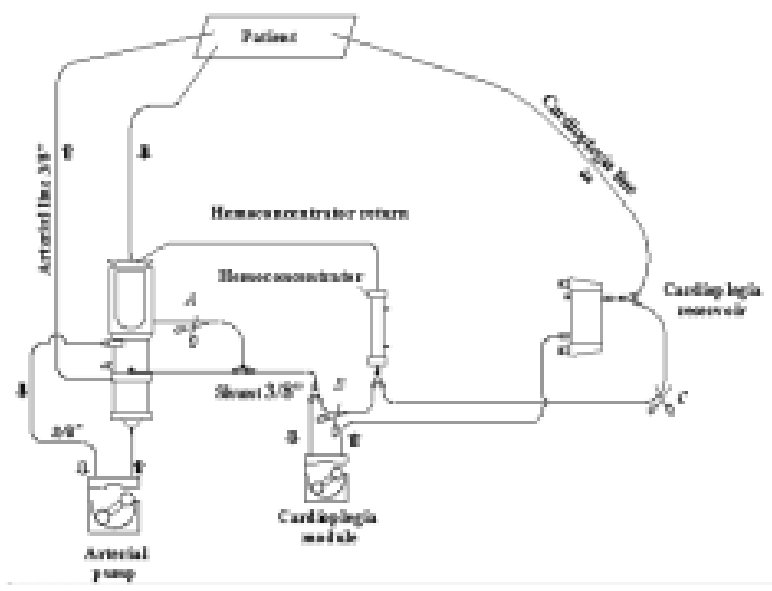

Fig. 1 - Cardiopulmonary bypass circuit showing the position of the hemoconcentrator (still not in use). A= clamping of the venous connection to the cardioplegia line; $\mathrm{B}=$ clamping of the inlet to the hemoconcentrator; $\mathrm{C}=$ clamping of the outlet of the cardioplegia system at the inlet of the hemoconcentrator.

The $\mathrm{CPB}$ circuit was filled with a solution of ringer lactate (q.s.p.), $20 \%$ mannitol $(1 \mathrm{~g} / \mathrm{kg})$ and a quantity of globular concentrate determined by hemodilution calculation according to Kirklin \& Barratt-Boyes [14]. CPB circuit priming volumes varied from 1650 to $2000 \mathrm{~mL}$. A quantity of $15,000 \mathrm{IU}$ of heparin and $8.4 \%$ sodium bicarbonate empirically calculated according to the equation 1.5.BE.Vol/ 1200 , with $\mathrm{BE}=$ base excess and $\mathrm{Vol}=$ perfusate volume were used.

After heparization of the patient with $2 \mathrm{mg} / \mathrm{kg}$, the activated coagulation time (ACT) was measured and additional heparin was administered until the ACT was greater than 480 seconds according to the protocol of Bull et al. [15]. To establish the CPB circuit, the ascending aorta and the superior and inferior vena cavae were cannulated.

The $\mathrm{CPB}$ was conducted with a flow of 2.4 and $2.6 \mathrm{~L} / \mathrm{min} /$ $\mathrm{m}^{2}$ at isothermia with temperatures between 32 and $34^{\circ} \mathrm{C}$, utilizing the quantity of blood computed using the total and partial hemodilution calculation in the perfusate. During CPB the hematocrit rate was maintained between 25 and $30 \%$. The systemic vascular resistance was maintained between 900 and 1200 dinas.sec. $\mathrm{cm}^{-5}$. When the systemic vascular resistance was less than 900 dinas.sec. $\mathrm{cm}^{-5}$, noradrenalin ( 0.01 to $0.1 \mu \mathrm{g} / \mathrm{kg} / \mathrm{min}$ ) was administered endovenously and when it was greater than 1200 dinas.sec.cm ${ }^{-5}$ anesthetic drugs (midazolam 0.1 to $0.2 \mathrm{mg} / \mathrm{kg}$, sufentanil 0.5 to $1.0 \mu \mathrm{g} / \mathrm{kg}$ ) or sodium nitroprusside ( 1 to $8 \mu \mathrm{g} / \mathrm{kg} / \mathrm{min}$ ) were administered.

To optimize the use of the hemoconcentrator, the hemofiltration was determined by the transmembrane pressure according to the following equation: $\mathrm{TMP}=(\mathrm{Pi}+$ $\mathrm{Po}) / 2+\mathrm{PV}$, where $\mathrm{TMP}=$ transmembrane pressure $(\mathrm{mmHg})$, $\mathrm{Pi}=$ inlet pressure of the hemoconcentrator $(\mathrm{mmHg}), \mathrm{Po}=$ outlet pressure of the hemoconcentrator $(\mathrm{mmHg})$ and $\mathrm{PV}=$ the absolute pressure value of the suction at the outlet of the filter (mmHg). Pressures between 150 and $230 \mathrm{mmHg}$ correspond to 10 to $15 \mathrm{~mL} / \mathrm{min}$ of filtered volume and between 350 and $450 \mathrm{mmHg}$ to 40 to $75 \mathrm{~mL} / \mathrm{min}$.

The patients were divided in two groups. Group A consisted of 70 individuals, whose maintenance of hematocrit during $\mathrm{CPB}$ was achieved only by the infusion of blood and crystalloid solutions. Group B also consisted of 70 individuals, but maintenance of hematocrit levels was, when necessary, made by infusion of blood and crystalloid solutions but mainly by the use of hemoconcentration using a hemoconcentrator.

Calculation of the total and partial hemodilution in Group A patients was achieved according to the technique described by Kirklin \& Barratt-Boyes [14], using a $28 \%$ hematocrit rate.

In Group A, the infusion of the remaining volume in the arterial chamber of the oxygenator was achieved by inverting the arterial tube and suctioning the volume of the tubes and arterial chamber to the venous reservoir and infusing it in the saphenous vein by means of a connection of the venous reservoir to the cardioplegia system.

In the Group B patients, a 25\% hematocrit rate was 
considered because of the protection of the hemoconcentrator.

In Group B, the new technique was applied after establishing the $\mathrm{CPB}$ according to the following criteria:

1-When the hematocrit level was between 25 and $30 \%$ and the volume in the venous reservoir of the oxygenator was above the safe level according to the manufacturer's technical manual (Braile Biomedica), hemoconcentration was initiated (Figure 2) during the heating stage with the filtration flow between 10 and $15 \mathrm{~mL} / \mathrm{min}$ determined by means of a transmembrane pressure of between 150 and $230 \mathrm{mmHg}$;

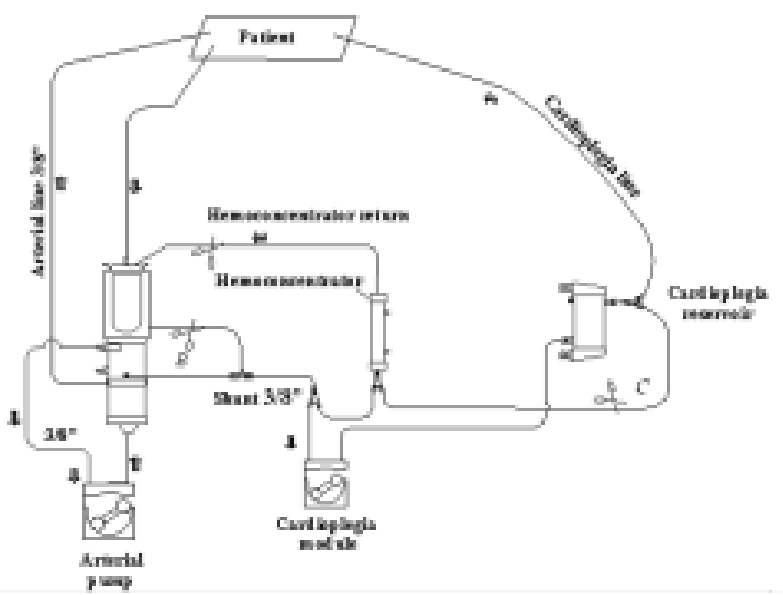

Fig. 2 - Cardiopulmonary bypass (CPB) circuit showing the hemoconcentrator and the cardioplegia system in use during $\mathrm{CPB}$. $\mathrm{A}=$ partial clamping of the outlet of the hemoconcentrator that returns to the venous reservoir; $\mathrm{B}=$ clamping of the venous connection to the cardioplegia line; $\mathrm{C}=$ clamping of the outlet of the cardioplegia system at the inlet of the hemoconcentrator.

2-When the hematocrit level was less than $25 \%$ and the volume in the oxygenator was lower than $800 \mathrm{~mL}$ up to the safety level specified by the oxygenator manufacturer, immediate infusion of from 300 and $400 \mathrm{~mL}$ of globular concentrate was made and subsequently, another blood sample was taken for assessment. If the hematocrit level had been corrected, hemoconcentration was initiated during the heating stage with the filtration flow of between 10 and $15 \mathrm{~mL} / \mathrm{min}$ determined by means of a transmembrane pressure of between 150 and $230 \mathrm{mmHg}$;

3 -When the hematocrit level is lower than $25 \%$ and the volume in the oxygenator greater than $800 \mathrm{~mL}$, hemoconcentration was initiated before the heating stage with the filtration flow rate of between 45 and $70 \mathrm{~mL} / \mathrm{min}$ determined by means of a transmembrane pressure between 350 and $450 \mathrm{mmHg}$ until the hematocrit level is greater than
$25 \%$ and from then on reducing the filtration flow rate to between 10 and $15 \mathrm{~mL} / \mathrm{min}$ determined by means of a transmembrane pressure of between 150 and $230 \mathrm{mmHg}$ with replacement of the crystalloid solution (ringer lactate $55 \mathrm{~mL}$ ) and magnesium sulfate $(10 \mathrm{~mL})$ with the filtration flow rate between 10 and $15 \mathrm{~mL} / \mathrm{min}$ to maintain the safety level of the venous reservoir of the oxygenator according to the technical specifications of the product and to avoid hypovolemia at the end of perfusion;

4-When the hematocrit levels were greater than $30 \%$, with the aim of avoiding hemolysis, an immediate infusion of crystalloid solution with a filtration flow rate of between 10 and $15 \mathrm{~mL} / \mathrm{min}$ irrespective of the volume in the oxygenator, until the hematocrit levels were between 25 and $30 \%$, initiating the hemoconcentration only during the heating phase.

CPB suspension was accomplished by gradually reducing the arterial flow rate and the fluid levels of the patient were adjusted using normalization of the hemodynamic data as parameters. The remaining volume from the venous reservoir was infused in the patient following the same aforementioned parameters.

After removal of the arterial cannula, a technique developed by the department to recovered hemoconcentration of the remaining blood in the circuit was used (Figures 3 and 4).

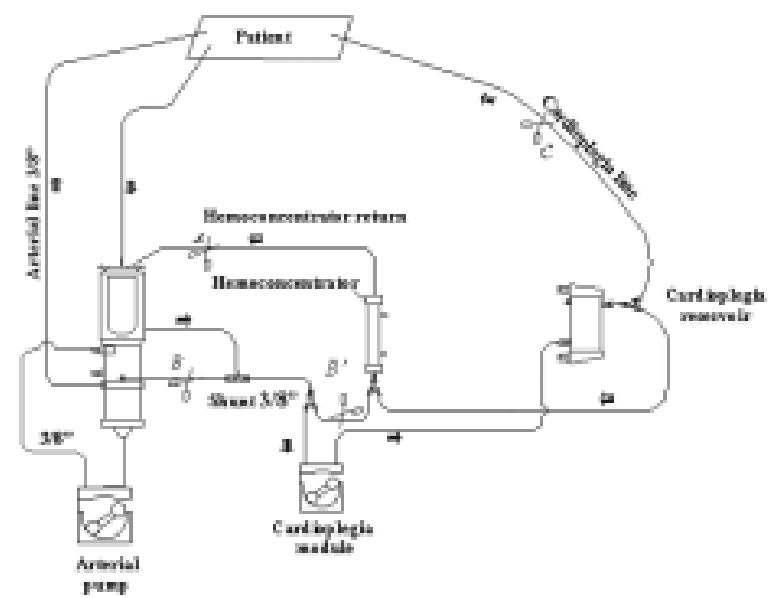

Fig. 3 - Cardiopulmonary bypass circuit showing the hemoconcentration of the remaining blood from the oxygenator. A $=$ partial clamping of the outlet of the hemoconcentrator that returns to the venous reservoir; $\mathrm{B} / \mathrm{B}^{\prime}=$ clamping of the recirculation line of the oxygenator and inlet of the hemoconcentrator; $\mathrm{C}=$ clamping of the outlet line of the cardioplegia to the patient. 


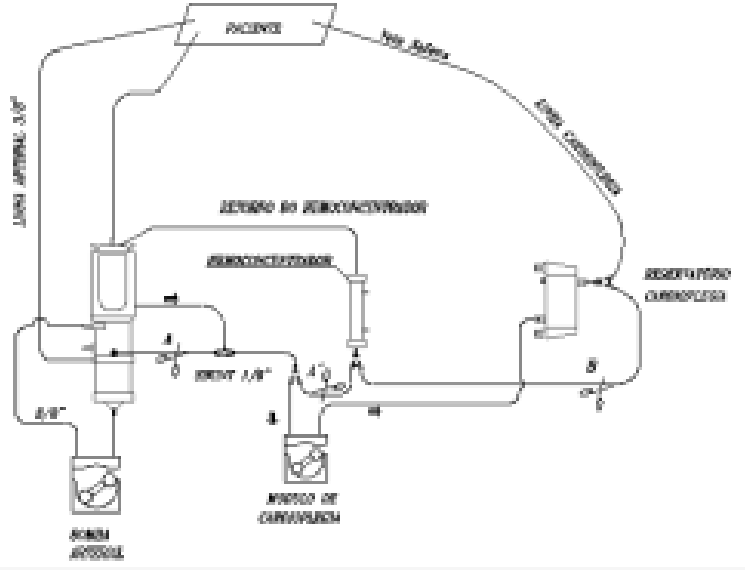

Fig. 4 - Cardiopulmonary bypass circuit showing re-infusion of the hemoconcentrated volume remaining in the oxygenator to the patient. $\mathrm{A} / \mathrm{A}^{\prime}$ = clamping of the recirculation line of the outlet of the oxygenator and inlet to the hemoconcentrator; $\mathrm{B}=$ clamping of the outlet line of the cardioplegia to the inlet of the hemoconcentrator.

For this technique the remaining blood in the arterial chamber of the membrane oxygenator was totally suctioned to the venous reservoir with the inversion of the arterial line and subsequently hemoconcentrated, with the help of the cardioplegia module until 30 to $40 \%$ of the liquid was removed. This concentrated blood was re-infused to the saphenous vein of the patient at a rate of 100 to $150 \mathrm{~mL} / \mathrm{min}$ utilizing the cardioplegia module, controlled by a measurement obtained in the left atrium in $\mathrm{cm}$ of water by means of a catheter introduced in this chamber, which normally ranges from 10 to $15 \mathrm{~cm}$.

Administration of protamine, which was calculated in a proportion of 1:1, was initiated before the infusion of the last $300 \mathrm{~mL}$ of concentrate of the volume remained in the arterial chamber of the oxygenator. In the ICU an additional $1 / 3$ of the calculated dose was infused over 4 hours.

\section{Statistical study}

A comparison of these variables in Groups A and B was performed utilizing the non-paired two-tailed Student t-test with Welch's correction when there were statistically significant differences between the standard deviations. A pvalue $<0.05$ was considered significant. The necessity of blood transfusions was analyzed comparing the patients from the two groups who did not receive blood and among those who received blood during $\mathrm{CPB}$, after the interruption of $\mathrm{CPB}$, in the immediate postoperative period and 24 hours after the surgical procedure. Analysis of these comparisons was achieved utilizing the Fisher Exact test. All calculations and analyses were performed using the Instat Graphpad computer program version 3.00 (Graphpad Software, San Diego, USA).

\section{RESULTS}

The initial hematocrit rates during CPB and the final values did not demonstrate significant differences between the two groups.

Diuresis in the patients of Group A varied from 50 to $1800 \mathrm{~mL}(532.43 \pm 351.22 \mathrm{~mL})$ whilst in Group B diuresis ranged from 0 to $1600(506.00 \pm 327.20 \mathrm{~mL})$. The difference between the two groups was not significant. Comparing the mean urine volume of the patients from both groups who did not receive blood (Group A $-561.11 \pm 355.86 \mathrm{~mL}$; Group $\mathrm{B}-535.00 \pm 291.37 \mathrm{~mL}$ ) with those who received transfusions (GroupA-522.50 $\pm 352.54 \mathrm{~mL}$; Group B $428.28 \pm 308.87 \mathrm{~mL}$ ), it was confirmed that patients who did not receive blood had a greater volume of urine, however without giving any significant differences.

The amounts of blood utilized during $\mathrm{CPB}$, after cessation of $\mathrm{CPB}$, in the immediate postoperative period and 24 hours after the surgical procedure are shown in Table 1. During and after the suspension of $\mathrm{CPB}$, the differences between Groups A and B were significant with lower values in Group B (pvalue $=0.0001$ and $p$-value $=0.0014$, respectively). In the immediate postoperative period and 24 hours after the surgical procedure there were no statistically significant differences between the two groups.

Table 1: Amount of blood (mL) utilized during cardiopulmonary bypass (B-CPB), after suspension of the $\mathrm{CPB}$ (B$\mathrm{pCPB}$ ), in the immediate postoperative period (B-IPO) and 24 hours after the surgical procedure (B-24) in patients submitted to heart surgery and comparison between Group A (without hemoconcentrator) and Group B (with hemoconcentrator)( SD = Standard deviation, $\mathrm{p}$-value $=$ level of significance)

\begin{tabular}{lllllc}
\hline & \multicolumn{2}{c}{ A } & \multicolumn{2}{c}{ B } & P-value \\
\hline & mean & sd & mean & sd & \\
B-CPB & 317,9 & 212,5 & 146,4 & 197,3 & $0,0001^{* * *}$ \\
B-pCPB & 157,1 & 204,9 & 48,6 & 187,3 & $0,0014 * *$ \\
B-IPO & 28,6 & 124,4 & 42,9 & 127,5 & $n$ s \\
B-24 & 188,6 & 131,4 & 210,7 & 231,7 & ns \\
\hline
\end{tabular}

$* * \mathrm{p}<0.01 \quad * * * \mathrm{p}<0.001 \mathrm{~ns}=$ not significant

The difference in the amount of plasma utilized after the cessation of CPB was significant between the two groups $(p$-value $=0.0001-$ Figure 5). During CPB, in the immediate postoperative period and 24 hours after the surgical procedure, there were no significant differences between the two groups. 


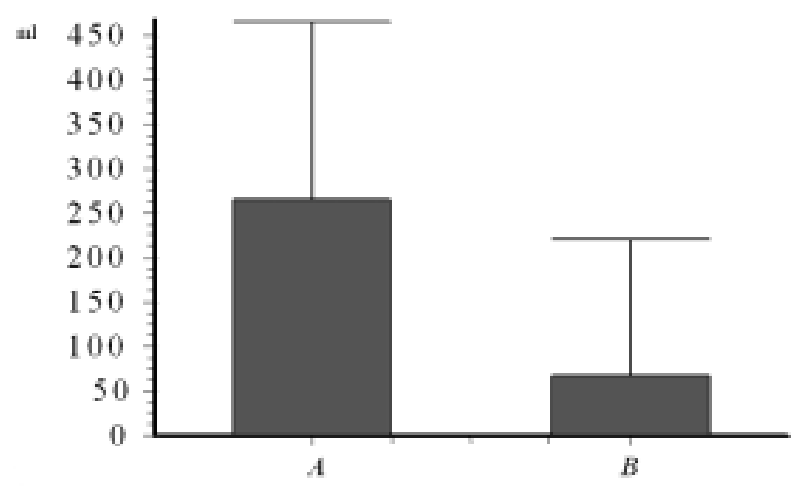

Fig. 5 - Amount of plasma utilized after suspension of the cardiopulmonary bypass in patients from Groups A and B submitted to heart surgery (mean \pm standard deviation). $\mathrm{P}$-value $=$ 0.0001

The positive fluid balance on suspension of CPB of the patients in Group A ranged from 460 to $3010 \mathrm{~mL}$ (1576.6 $538.41 \mathrm{~mL}$ ) and in Group B it varied from 1210 to $3650 \mathrm{~mL}$ $(780.43 \pm 923.54 \mathrm{~mL})$. On comparing the means of Groups A and $\mathrm{B}$, a significant difference was evidenced with lower values in Group B (p-value = $0.0001-$ Figure 6).

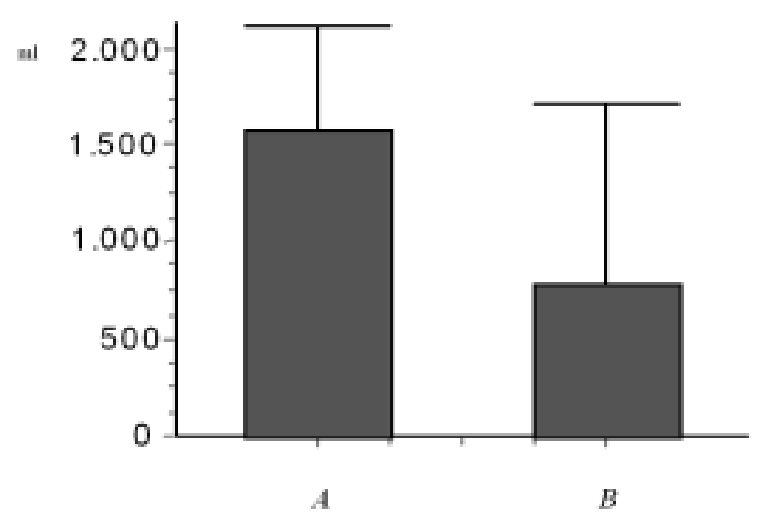

Fig. 6 - Fluid balance at suspension of cardiopulmonary bypass in patients from Groups A and B submitted to heart surgery (mean \pm standard deviation). $\mathrm{P}$-value $=0.0001$

The CPB time of the Group A patients varied from 34 to 155 minutes ( $80.81 \pm 23.6$ minutes) and the Group B patients ranged from 29 to 222 minutes ( $87.73 \pm 32.98$ minutes) without demonstrating any significant difference between the two groups.

During CPB, 18 patients of Group A and 41 of Group B did not receive blood transfusions, confirming a significant difference between the two groups with a lesser necessity in Group B (p-value $=0.0001)$.
After suspension of CPB, 40 individuals in Group A and 62 in Group B did not receive blood transfusions, showing a significant difference in favor of Group B ( $p$-value $=0.0001$ ). In the immediate postoperative period there were no blood transfusions in 66 patients of Group A and 62 in Group B without significant difference. In 34 individuals of Group A and 42 of Group B, there were no blood transfusions 24 hours after the surgical procedure without any significant difference.

During CPB, the mean volume of blood received by the patients of Group A was $428 \pm 114 \mathrm{~mL}(\mathrm{n}=52)$ and of Group B $353 \pm 142 \mathrm{~mL}(\mathrm{n}=29)$. The difference between the groups was significant $(\mathrm{p}$-value $=0.05)$.

After the interruption of $\mathrm{CPB}$, the individuals of Group A and $B$ received $367 \pm 143 \mathrm{~mL}(\mathrm{n}=30)$ and $425 \pm 404 \mathrm{~mL}(\mathrm{n}=$ 8) of blood respectively, without significant difference.

In the immediate postoperative period, the volume of transfused blood in Group A was $500 \pm 204 \mathrm{~mL}(\mathrm{n}=4)$ and in Group B $375 \pm 134 \mathrm{~mL}(\mathrm{n}=8)$, again without significant difference.

In Groups A and B, 24 hours after the surgical procedure, the volume of transfused blood was $393 \pm 209 \mathrm{~mL}(\mathrm{n}=28)$ and $410 \pm 148 \mathrm{~mL}(\mathrm{n}=36)$, respectively without significant difference.

In the patients from Group A, the length of time in the ICU varied from 1 to 11 days ( $3.7 \pm 1.8$ days). In Group B, this period varied from 0 to 23 days $(3.3 \pm 2.7)$. There was no significant difference.

In the patients of Group A, the postoperative period lasted for 5 to 32 days ( $8.4 \pm 3.8$ days) and of Group B the period lasted 1 to 35 days ( $8.7 \pm 5.3$ days) giving a nonsignificant difference.

\section{DISCUSSION}

The new technique of hemoconcentration utilized during on-pump heart surgery by the department proved to be feasible, it did not present with problems setting up the CPB circuit or in its administration, performing the procedure without adverse effects. Also the technique did not increase the risk of complications for the patient in the intra- and postoperative periods.

The necessity of transfusion of blood components was less in patients submitted to on-pump heart surgery employing hemoconcentration. In the operations of these patients, the quantities of blood utilized during and after $\mathrm{CPB}$, and of plasma after $\mathrm{CPB}$, were significantly less in relation to individuals in which the hemoconcentrator was not used. Additionally, the liquid balance after $\mathrm{CPB}$ with the hemoconcentrator was less when compared to that obtained without this equipment.

The speed of filtration for hemoconcentration to be 
performed during CPB is dependent on the hematocrit level, the volume of the venous reservoir and before the infusion of the remaining volume (arterial and venous blood) of the oxygenator in the patient.

Of the methods of hemoconcentration utilized, the modified compared to the conventional method, was more efficient in removing the excessive fluid [13]. However, to take advantage of the blood remaining in the oxygenator, crystalloid solution is used to force the blood from the venous reservoir to the arterial chamber.

It is important to stress that the volume of blood contained in the arterial tube and the filter of the arterial line (approximately $300 \mathrm{~mL}$ ) is normally disregarded which occurs in both conventional and modified hemofiltration. This blood can be reused, as according to WALPOTH et al. [7] and BOLDT et al. [17], the blood submitted to hemofiltration during CPB presents with a good quality.

Several ways of dealing with the blood remaining in the oxygenator have been utilized around the world in Heart Surgery Departments, including techniques that disregard the entire volume of the arterial blood in the oxygenator, to those in which crystalloid solution is added to force the blood to the venous reservoir [13], and those in which there is a transference of arterial blood to the cardioplegia reservoir for infusion in the venous access. In some services, a cell saver is even used to wash the red blood cells by means of centrifugation [17].

In the cases in which the volume of arterial blood of the oxygenator (approximately $1,300 \mathrm{~mL}$ ) is overlooked, the opportunity to re-infuse good quality blood is lost [7]. In other situations, the blood is not totally utilized so there is still a considerable loss (approximately 500 to $700 \mathrm{~mL}$ ). When the blood is forced using the crystalloid solution, hemodilution occurs and a reduction in the hematocrit levels of from 25 to $30 \%$ to around 12 or $18 \%$ occur. When the cell saver is used, only the red blood cells are re-used and the platelets and plasma with their coagulation elements are lost [18].

Different to the aforementioned techniques, in the present study the inversion of the arterial tube to suction of the blood from the tube, filter and arterial chamber to the venous reservoir, enabled a new hemoconcentration of the remaining volume $(800 \mathrm{~mL})$ through the diversion of the cardioplegia line and in the outlet of the cardioplegia system to the inlet of the hemoconcentrator by means of rollers of the cardioplegia module, removing $30 \%$ to $40 \%$ of the solute and increasing the hematocrit levels of the remaining blood from $25 \%$ to $30 \%$ during $\mathrm{CPB}$ to $35 \%$ to $40 \%$ before reinfusion.

The amount of blood transfused during CPB was less in the patients of Group B, resulting mainly in a reduction of the use of donor blood in the CPB pump.
Several authors mention the advantages in the reduction of the use of blood during $\mathrm{CPB}$, such as the reduction in the demand from blood banks [19], the risk of diseases (hepatitis and AIDS) [20], transfusion reactions and coagulation disorders [21].

After CPB, the quantities of blood and plasma transfused were less in the patients of Group B. In this phase, the lower volume of blood utilized by the patients of this group was owing to the lack of necessity to transfuse blood during the procedure to revise the hemostasis and surgical closure of the patient, as the final hematocrit rate of the Group B individuals presented with a mean of $33.7 \%$ ( 29 to $42 \%$ ), close to the standards utilized by the service. The lower quantity of plasma utilized in this group was due to the possibility of using a larger amount of crystalloid solution.

The fluid balance on CPB suspension presented with significantly lower values in patients of Group B. This is owing to the fact that the hemoconcentrator was efficacious in removing the excess of fluids originating from the composition of the perfusate of the CPB circuit.

The volume and the necessity of blood transfusion, both during and after $\mathrm{CPB}$ cessation, in the patients who received or did not receive blood in the perfusate, was less in Group B, reinforcing the importance of the technique of hemoconcentration to reduce the use of blood components.

Despite of the successful use of this technique, it is worth stressing that the technique can still be improved. A suggestion would be the filling of the tube, filter and arterial chamber, during suction of the residual blood, with a crystalloid solution by means of the arterial cannula, with the inlet to the filter of the arterial line clamped, aiming at avoiding a backflow of the elements filtered during CPB such as the micro-aggregated platelets and particles. Thus, a greater amount of blood could be hemoconcentrated, increasing the volume to be reinfused and maintaining the system completely full, avoiding its aeration and not impeding eventual backflow. Perhaps a disadvantage would be an increase of 5 to 10 minutes to finish the hemoconcentration process.

Alternative methods that reduce the necessity of blood and blood component transfusion during on-pump heart surgery are needed. In the USA, transfusions made in heart surgeries utilize $20 \%$ of the stocks of blood banks [20] Recently, blood transfusions have been related to postoperative complications in heart surgeries such as sternal infection, pneumonia, renal dysfunction, severe septicemia and hospital mortality. Additionally, the transfusions have been associated with an increase in the long-term mortality rates [22].

A retrospective analysis of 1915 patients submitted to on-pump heart surgeries (164 received blood transfusions in the intra-operative period, 303 in the postoperative period 
and 192 in both), Engoren et al. [22] confirmed that the period of hospitalization was $10 \pm 12$ days for those who were transfused and $5 \pm 2$ days for the patients who did not receive blood. Additionally, the mortality rate up to 5 years after the procedure was significantly greater in the individuals who received transfusions ( $15 \%$ versus $7 \%)$.

However, apart from reducing the demand from the blood banks and diminishing the costs, a reduction of blood transfusions could result in a reduction of postoperative complications and, in particular, of long-term mortality rates in patients submitted to on-pump heart surgery.

\section{CONCLUSIONS}

This new technique of hemoconcentration used during on-pump heart surgery was efficacious in the removal of fluids and allowed a greater utilization of the blood remaining in the oxygenator and a lesser necessity of blood component transfusion.

\section{BIBLIOGRAPHIC REFERENCES}

1. Gibbon Jr. JH. Application of a mechanical heart and lung apparatus to cardiac surgery. Minn Med 1954; 37:171-85.

2. Souza MHL, Elias DO. Fundamentos de circulação extracorpórea. Rio de Janeiro: Centro Editorial Alfa Rio;1995.

3. Foote AV, Trede M, Maloney Jr. JV. An experimental and clinical study of the use of acid-citrate-dextrose (ACD) stored blood for extracorporeal circulation. J Thorac Cardiovasc Surg 1961;42:93-109.

4. Panico FG, Neptune WB. A mechanism to eliminate the donor blood prime from the pump-oxygenator. Surg Forum 1959;10:605-9.

5. Morais DJ, Franco SA, Jasbik W, Sader J. Circulação extracorpórea prolongada com hemólise mínima (uso de plasma no oxigenador em substituição ao sangue). Rev Bras Cir 1960;39:129-32.

6. Walpoth BH, von Albertini B. Ultrafiltration in cardiac surgery. J Extra Corp Technol 1984;16:68-72.

7. Walpoth BH, Amport T, Schmid R, Kipfer B, Lanz M, Spaeth $\mathrm{P}$ et al. Hemofiltration during cardiopulmonary bypass: quality assessment of hemoconcentrated blood. Thorac Cardiovasc Surg 1994;42:162-9.

8. Kiziltepe U, Uysalel A, Corapcioglu T, Dalva K, Akan H, Akalin H. Effects of combined conventional and modified ultrafiltration in adult patients. Ann Thorac Surg 2001;71:684-93.
9. Yndgaard S, Andersen LW, Andersen C, Petterson G, Baek L. The effect of modified ultrafiltration on the amount of circulating endotoxins in children undergoing cardiopulmonary bypass. J Cardiothorac Vasc Anesth 2000;14:399-401.

10. Marenzi G, Lauri G, Grazi M, Assanelli E, Campodonico J, Agostoni P. Circulatory response to fluid overload removal by extracorporeal ultrafiltration in refractory congestive heart failure. J Am Coll Cardiol 2001;38:963-8.

11. Sant'Anna JR, Biscegli J, Kalil RA, Luchese FA, Prates PR, Nesralla IA. Ultrafiltração paralela em cirurgia cardíaca. Arq Bras Cardiol 1988;51:161-5.

12. Maluf MA, Mangia C, Bertuccez J, Silva C, Catani R, Carvalho $\mathrm{W}$ et al. Estudo comparativo da ultrafiltração convencional e associação de ultrafiltração convencional e modificada na correção de cardiopatias congênitas com alto risco cirúrgico. Rev Bras Cir Cardiovasc 1999;14:221-36.

13. Naik SK, Knight A, Elliott M. A prospective randomized study of a modified technique of ultrafiltration during pediatric open-heart surgery. Circulation 1991;84(5 suppl):II422-31.

14. Kirklin JK, Barratt-Boyes BG. Cardiac surgery. $2^{\text {nd }}$ ed. New York: Churchill Livingstone;1993.

15. Bull BS, Korpman RA, Huse WM, Briggs BD. Heparin therapy during extracorporeal circulation: problems inherent in existing heparin protocols. J Thorac Cardiovasc Surg 1975;69:674-84.

16. Braile DM, Zaiantchik M, Ramin SL, Volpe MA, Souza DRS. Continuous normothermic blood cardioplegia in myocardium revascularization. L'Information Cardiologique 1993;17:256-61.

17. Boldt J, Kling D, von Bormann B, Züge M, Scheld H, Hempelmann G. Blood conservation in cardiac operations: cell separation versus hemofiltration. J Thorac Cardiovasc Surg 1989;97:832-40.

18. Solem JO, Tengborn L, Steen S, Luhrs C. Hemofiltration versus centrifugation for concentration of oxygenator residual content. J Cardiovasc Surg 1987;35:42-7.

19. Verska JJ, Ludington LG, Brewer LA. A comparative study of cardiopulmonary bypass with nonblood and blood prime. Ann Thorac Surg 1974;18:72-80.

20. Spiess BD. Transfusion and outcome in heart surgery. Ann Thorac Surg 2002;74:986-7.

21. Tector AJ, Gabriel RP, Mateicka WE, Oparah SS, Flemma RJ, Lepley Jr. D. Reduction of blood usage in open heart surgery. Chest 1976;70:454-7.

22. Engoren MC, Habib RH, Zacharias A, Schwann TA, Riordan CJ, Durham SJ. Effect of blood transfusion on long-term survival after cardiac operation. Ann Thorac Surg 2002;74;1180-6. 